\title{
Implicações das relações parentais para a terminologia de parentesco consanguíneo em Mehináku (Arawak)
}

DOI: http://dx.doi.org/10.21165/el.v49i2.2468

\section{Paulo Henrique Pereira Silva de Felipe ${ }^{1}$}

\section{Resumo}

A relação entre língua e cultura, e o modo como esses dois âmbitos da vida humana estão imbricados, tem encontrado guarida, há séculos, tanto na linguística quanto na antropologia. Dentre os temas que emergem dessa relação está o parentesco, que é foco de ambas as áreas porque está associado tanto a um sistema terminológico, e por isso figura como um tema linguístico, quanto a um sistema de atitudes que designa um conjunto de relações sociais entre indivíduos, e por isso está associado à antropologia. Neste trabalho, vamos apresentar uma descrição da terminologia de parentesco consanguíneo do povo Mehináku, a fim de verificar como se dá a nomeação dos entes familiares entre esse povo, e, mais, como essa terminologia pode variar a depender da relação que se estabelece entre nomeador e nominado. O povo Mehináku é falante de uma língua de mesmo nome, pertencente à família linguística Arawak, e falada por aproximadamente 400 pessoas que vivem às margens ou nas proximidades do Rio Kurisevo, no Território Indígena do Xingu, MT, Brasil.

Palavras-chave: terminologia de parentesco; língua Mehináku; família Arawak.

1 Universidade Estadual de Campinas (UNICAMP), Campinas, São Paulo, Brasil; pauloh2sp@gmail.com; https://orcid.org/0000-0001-6607-5417 


\title{
Implications of Parental Relations for Mehináku (Arawak) Consanguineous Terminology
}

\begin{abstract}
The relationship between language and culture, and the way in which these two areas of human life are intertwined, has found shelter for centuries in both linguistics and anthropology. Among the themes that emerge from this relationship is kinship, which is a focus because it is associated with both a terminological system (linguistics) as well as a system of attitudes that designates a set of social relations between individuals (anthropology). In this project work, we will present a description of the terminology of inbreeding kinship of the Mehináku people, in order to verify how the family members are appointed among these people and, moreover, how this terminology may vary depending on the relationship established between nominator and nominee. The Mehináku people speak an eponymous language belonging to the Arawakan language family and spoken by approximately 400 people who live in or near the Kurisevo River, in the Xingu Indigenous Territory, MT, Brazil.
\end{abstract}

Keywords: kinship terminology; Mehináku language; Arawakan family.

\section{Introdução}

A relação entre língua e cultura e o modo como esses dois âmbitos da vida humana estão imbricados têm encontrado, há séculos, guarida tanto na linguística quanto na antropologia e em áreas afins. Dentre os temas que emergem dessa relação, está o parentesco, uma área relativamente nova, se comparada a outros estudos de natureza linguística e antropológica. O parentesco é foco da linguística e da antropologia porque está associado tanto a um sistema terminológico, a um vocabulário, e por isso figura como um tema linguístico, quanto a um sistema de atitudes que designa um conjunto de relações sociais entre indivíduos de determinados grupos, e por isso está associado de modo contíguo à antropologia.

O estudo sistemático a respeito das terminologias de parentesco se inicia somente no final do século XIX, a partir do trabalho Systems of Consanguinity and Affinity of the Humam Family, de Lewis Morgan (1997 [1868]), em que o autor apresenta um estudo abrangente e não submetido a elaborações legais e jurídicas da parentela, como se fazia na Roma antiga pelos juristas, ou a observar as relações familiares. Em sua obra, aparece, pela primeira vez, a possibilidade de se estudar a forma como determinadas pessoas são classificadas de acordo com diferentes culturas. Em Morgan, a terminologia de parentesco ganha existência enquanto sistema e passa a constituir-se como um objeto próprio de estudo (FLORIDO, 2008). 
Desde então, muitos outros trabalhos, sobretudo aqueles de viés antropológico, vieram somar-se ao de Morgan, de modo que os estudos a respeito das relações de parentesco e das terminologias utilizadas por diferentes povos para caracterizar as relações parentais, ganharam evidência. A própria estruturação do parentesco feita por Morgan, por exemplo, sofreu diversas modificações, à medida em que foram surgindo novas proposições teóricas e estudos de natureza também empírica, como se pode ver em McLennan (1998), Radcliffe-Brown (1941) e outros.

A fim de tratarmos, então, da terminologia de parentesco na língua Mehináku, dividimos este artigo em três seções: (i) na primeira, apresentaremos a língua e o povo Mehináku; (ii) na segunda, apresentaremos a fundamentação teórica deste trabalho e (iii) na terceira seção, mostraremos como se dá a nomeação dos entes familiares entre esse povo, e, mais, como essa terminologia pode variar a depender da relação que se estabelece entre nomeador e nominado.

\section{A língua e o povo Mehináku}

O povo Mehináku é falante de uma língua de mesmo nome, pertencente à família linguística Arawak, e falada por aproximadamente 400 pessoas que vivem às margens ou nas proximidades do Rio Kurisevo, no Território Indígena do Xingu, MT, Brasil. A população distribui-se em quatro aldeias, são elas: (i) Uyaipiyuku, que é a mais antiga e da qual derivaram as demais aldeias; (ii) Utawana, a segunda maior; (iii) Kaupüna e (iv) Aturua.

A aldeia Utawana é a mais próxima da cidade, localizada a cerca de 35 quilômetros da cidade de Gaúcha do Norte (MT) e mantém certa proximidade com as aldeias Kaupüna e Aturua, de modo que é possível se locomover de uma a outra mais rapidamente, usando carro, na época da baixa do rio, ou barco, no período de cheia. A aldeia Uyaipiyuku, por sua vez, é a mais distante das quatro mencionadas anteriormente, e está situada a aproximadamente 4 horas de viagem de barco da aldeia de Utawana. Os dados que serviram de base para a realização deste trabalho foram coletados durante nossos trabalhos de campo na aldeia Utawana, entre 2016 e 2019, e complementados com coletas realizadas na cidade de Campinas, a ocasião da vinda de alguns indígenas para esta cidade. 
Figura 1. Localização dos Mehináku

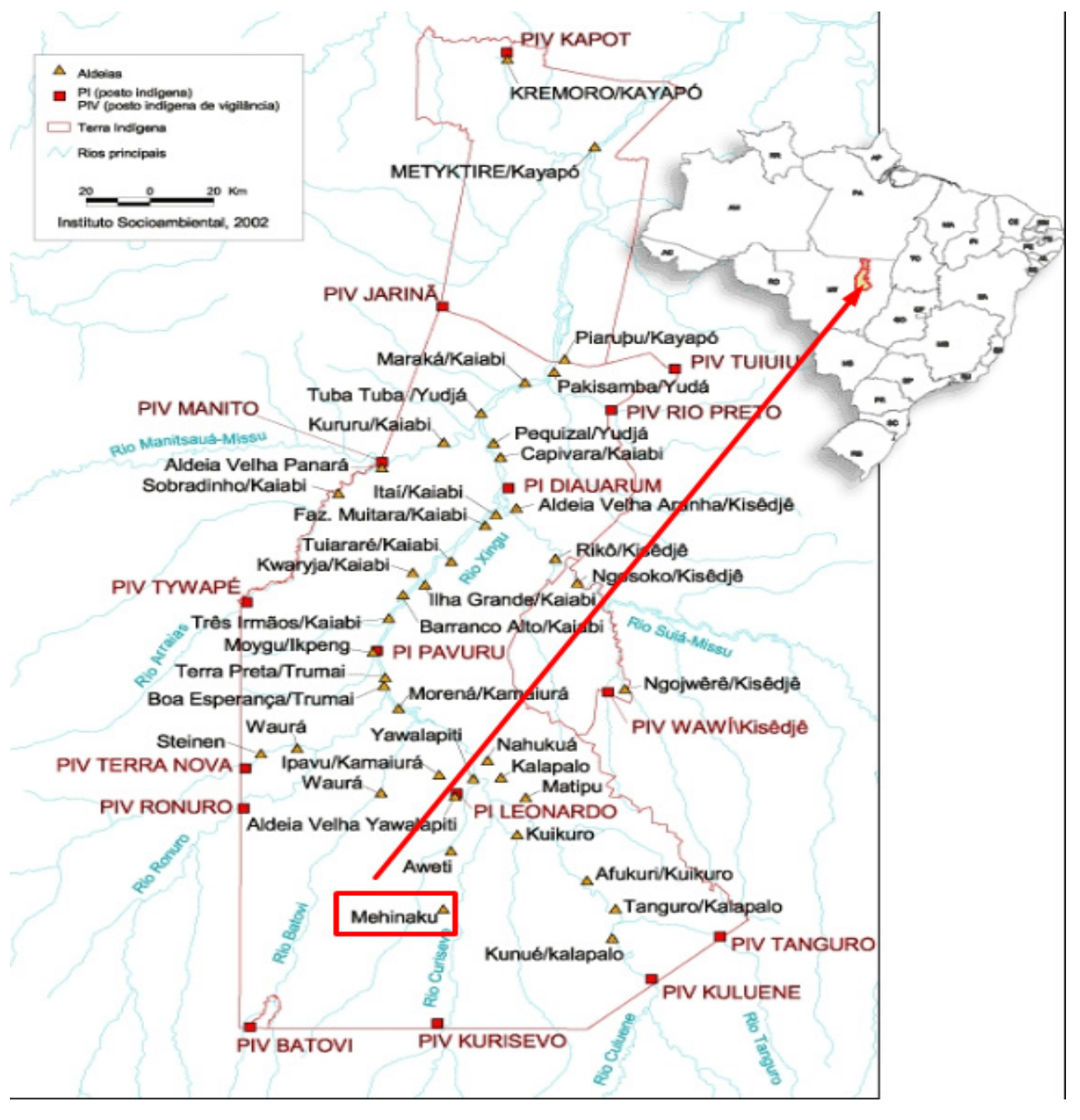

Fonte: ISA (2008, destaque nosso)

\section{Questões teóricas sobre a terminologia de parentesco}

De acordo com Morgan (1997 [1981]), os sistemas de parentesco em línguas humanas são estabelecidos levando-se em consideração dois princípios mentais básicos (ou socioculturais) que existem universalmente, quais sejam: o princípio de afinidade, e o princípio de consanguinidade ou filiação. O primeiro desses princípios se refere às relações acordadas entre grupos sociais distintos, por meio do casamento de um homem e uma mulher, sendo um de cada grupo. Nesse caso, não significa somente a ligação entre duas pessoas de sexos distintos, mas, sobretudo, a união dos grupos aos quais essas pessoas pertencem. O segundo princípio, por sua vez, como sugere o próprio nome, versa sobre a relação consanguínea, na qual se agrupam pessoas que partilham o mesmo patrimônio genético, como pai, mãe, filho, filha, avô, avó etc. 
Morgan foi o fundador do método comparativo estrutural e responsável por elaborar uma tipologia para as relações parentais e matrimoniais. Para o autor, era mais importante a comparação dos "sistemas de relações", e não propriamente dos termos de parentesco, uma vez que os primeiros é que eram os responsáveis por conectar entre si os termos contidos nas terminologias de parentesco. Morgan demonstrou, a partir da tabulação de um conjunto de "sistemas de relações", que essas relações poderiam ser agrupadas em dois tipos: os "sistemas descritivos" e os "sistemas classificatórios". Os primeiros seriam característicos de todos os povos indígenas norte-americanos, com exceção dos Esquimó, dos povos do sul da Índia, da China, do sudeste asiático e do Pacífico, que seriam considerados povos mais "atuais", enquanto os segundos, ou seja, os "sistemas classificatórios" seriam característicos dos povos mais "primitivos". Nas palavras de Almeida (2010, p. 311):

\begin{abstract}
Esse resultado, embora representasse para Morgan a evidência da unidade dos povos indígenas norte-americanos, e de sua unidade com povos asiáticos, colocava um enigma. Tratava-se de explicar a própria existência dos "sistemas classificatórios", que eram, de um lado, característicos de povos não civilizados e, por outro lado, eram mais artificiais, mais elaborados e mais distantes da "natureza da descendência" do que os "sistemas descritivos" dos povos "civilizados"2.
\end{abstract}

Em síntese, o método de Morgan consistiu em comparar estruturalmente e organizar de forma tabular um conjunto de 39 povos das famílias semítica, ariana e uraliana, 80 povos das famílias ganowaniana (índios norte-americanos (com exceção dos Esquimó), com os Sêneca-iroqueses como caso representativo) e Esquimó, e 18 povos das famílias turaniana (falantes de línguas dravidianas do sul da Índia, com o Tamil como caso representativo) e malaia, num total de 147 casos (ALMEIDA, 2010). 0 autor acreditava, sobretudo, numa relação de primazia das práticas sobre os termos de parentesco.

A respeito desta relação entre terminologia e práticas de parentesco, Florido (2008) argumenta que, embora a ideia de relacionar termos de parentesco e práticas matrimoniais seja tão antiga quanto os estudos antropológicos sobre o tema, a concepção da relação possui grande variação ao longo da história. Há autores, segundo ele, que acreditam numa estreita relação entre a terminologia de parentesco e as relações parentais, enquanto há outros que sequer acreditam numa possível relação.

2 De acordo com Almeida (2016), a solução para a existência dos "sistemas classificatórios" foi proposta por Morgan em um artigo publicado separadamente em $1868 \mathrm{com}$ o título A Conjectural Solution of the Origin of the Classificatory System of Relationship. É essa uma das duas obras de Lewis Morgan que Darwin cita com respeito em The Descent of Man (DARWIN, 2004 [1871], p. 170, nota 35; p. 655, nota 5; p. 661, nota 14). 
Rivers (1991a [1913]), em seu trabalho de campo na Melanésia, por exemplo, foi um dos primeiros a descobrir relações de correspondência entre os termos de parentesco e as relações que eles assinalam. O autor percebeu em seu trabalho de campo que, em regiões onde há casamento de primos cruzados bilaterais, um homem ao casar passa a considerar o irmão da sua mãe também como o pai de sua esposa, e que o irmão de sua mãe passa a considerá-lo não apenas como filhos de sua irmã, mas também como marido de sua filha (o que é lógico, se considerarmos a primeira relação estabelecida, em que o homem casado considera o próprio tio materno como pai de sua esposa).

Tanto Rivers quanto Morgan, por exemplo, acreditavam numa precedência das práticas parentais sobre as terminologias de parentesco, o que pode acarretar, de acordo com Florido (2008, p. 95), análises que correspondem a reconstruções históricas especulativas, na tentativa de explicar as terminologias:

As práticas matrimoniais influenciam sim o componente semântico do parentesco, como o próprio Rivers concordaria, o problema está em acreditar que deva existir, necessariamente, o comportamento que melhor corresponda à terminologia e, na ausência deste, tomar a não correspondência como indicação das formas passadas.

Se existe uma univocidade total entre esses domínios, não cabe a nós discutir neste trabalho. Sob a ótica dessa discussão, optamos por acreditar num ponto intermediário entre essas questões, sobretudo porque acreditamos que exista uma relação entre a terminologia empregada para designar as relações de parentesco e as próprias práticas parentais, mas não acreditamos, por exemplo, que haja uma correspondência total entre os dois domínios, de modo que cada termo revelasse a totalidade das relações e práticas de parentesco das sociedades humanas. Conforme defende Lévi-Strauss (1969 [1965]), embora a terminologia aja como operador de um sistema matrimonial, não há relação de causalidade imediata entre os dois domínios.

A respeito dos Mehináku, veremos na seção seguinte que a terminologia de parentesco mantém uma relação contígua com as relações parentais, em especial no que se refere ao casamento entre primos cruzados e o modo como esses entes passam a ser referidos e a referir-se a outros entes parentais. Antes, porém, de tratarmos das relações e da terminologia de parentesco na língua, é preciso explicar a formalização que iremos utilizar na análise.

A notação mais comum para a grafia de relações de parentesco é a inglesa, na qual os marcadores dos kin types são formados pela primeira letra do termo de parentesco em inglês. Vejamos a abreviação dos termos: 


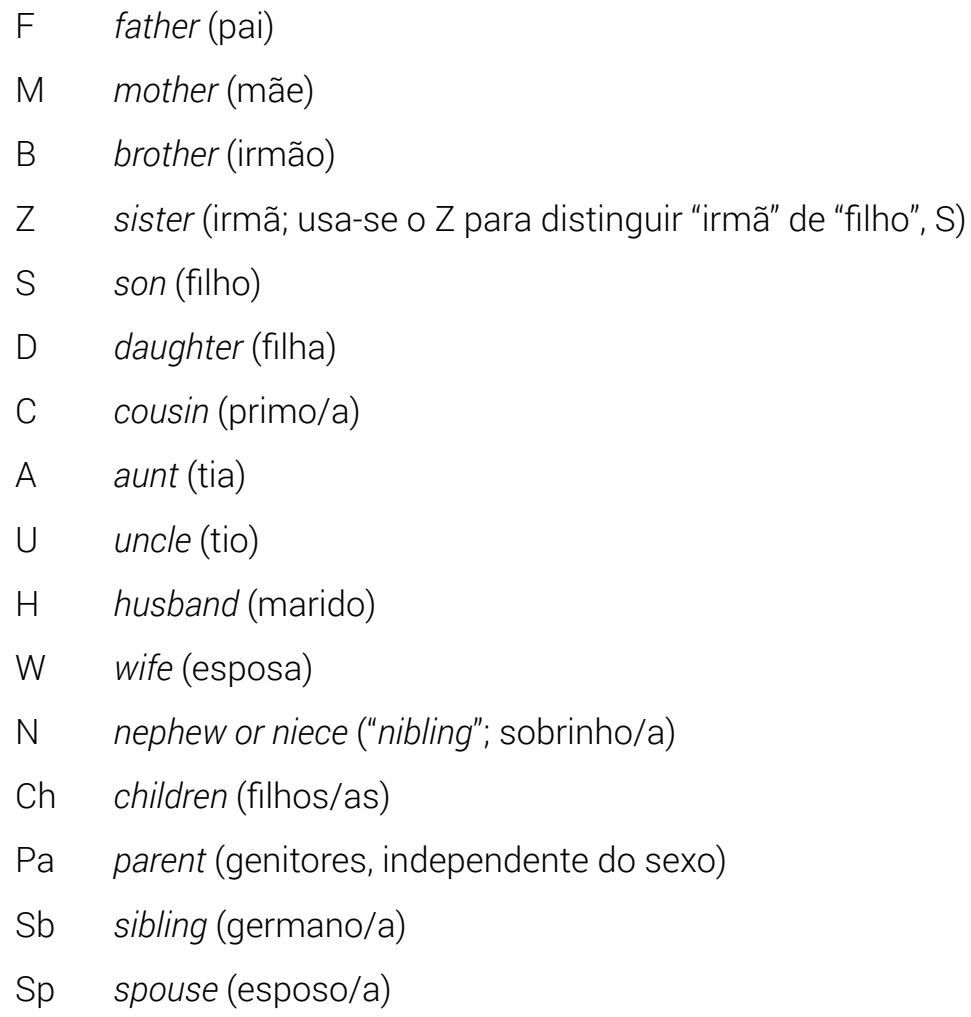

Os termos compostos, formados a partir da união dos termos apresentados acima, devem ser lidos sempre da direita para a esquerda, de modo que a leitura é feita da seguinte forma:

$\begin{array}{ll}\text { FM } & \text { Mãe (M) do pai (F) } \\ \text { MZS } & \text { Filho (S) da irmã (Z) da mãe (M) } \\ \text { FBD } & \text { Filha (D) do irmão (B) do pai (F) }\end{array}$

Além disso, existem marcadores de idade relativa, utilizados quando se quer indicar que determinado parente é mais velho ou mais novo que outro, conforme abaixo:

e $\quad$ elder (mais velho). Exemplos:

eB (elder Brother 'irmão mais velho);

MeZ (Mother's elder (Z)sister 'irmã mais velha da mãe'

y younger (mais novo). Exemplos:

yB (younger Brother 'irmão mais novo')

Quanto às gerações, utilizam-se também alguns termos para marcar gerações ascendentes e descendentes, da forma como segue: 


$\begin{array}{ll}\mathrm{G}^{3} \text { ou G+3 } & \text { geração dos bisavós } \\ \mathrm{G}^{2} \text { ou G+2 } & \text { geração dos avós } \\ \mathrm{G}^{1} \text { ou G+1 } & \text { geração dos pais } \\ \mathrm{G}^{0} & \text { geração de Ego } \\ \mathrm{G}^{-1} & \text { geração dos filhos } \\ \mathrm{G}^{-2} & \text { geração dos netos } \\ \mathrm{G}^{-3} & \text { geração dos bisnetos }\end{array}$

Usaremos também, para demonstrar os esquemas de parentesco, esquemas de gráficos de laços. A simbologia adotada inclui um triângulo para o homem e um círculo para a mulher, conforme é praxe na literatura antropológica. Estes símbolos não possuem nenhum preenchimento. Entretanto, o gráfico sempre analisa os laços de parentesco a partir de um EGO (masculino ou feminino), e este símbolo, para melhor visualização, está diferenciado no trabalho na cor preta (está preenchido de preto, enquanto os demais estão sem preenchimento) ou assinalado com o nome EGO embaixo do símbolo gráfico que o representa. As linhas paralelas indicam casamento.

\section{A terminologia de parentesco em Mehináku}

De acordo com Coelho de Souza (1995), os Mehináku, assim como os demais grupos xinguanos, não possuem linhagens ou distorções patri ou matrilineares no cálculo do parentesco, sendo este gradual. De acordo com a autora, existem aqueles que para os Mehináku são mais parentes e aqueles que são menos parentes, e este tipo de categorização é determinada pelas atitudes recíprocas, pela quantidade e intensidade da interação entre os indivíduos.

Gregor (1982), por sua vez, afırma que a graduação do parentesco forma um continuum para os Mehináku, distinguindo quatro classes de pessoas, do ponto de vista de um indivíduo: os (i) "parentes verdadeiros" (epene ou epenewaja), que inclui os parentes biológicos com quem é possível traçar relações genealógicas; os (ii) "um pouco parentes" (epenehatâi), que são as pessoas que se acredita compartilharem um ancestral comum, mas cuja ligação é remota ou desconhecida (aqui são incluídos os habitantes da aldeia que não são considerados parentes verdadeiros); os (iii) "parentes fictícios" (penerí), que não são considerados parentes, ou com os quais não se reconhece a existência de conexões genealógicas (incluem-se indivíduos de outras aldeias com quem se mantêm relações ou de quem se quer aproximar) e, finalmente, os (iv) "não parentes" (neuneihete), que inclui as pessoas com as quais não se reconhece nenhuma ligação ou relação de parentesco (não-indígenas, em geral, quando não há estreita proximidade de um homem branco ou mulher branca com um indivíduo Mehináku). 
Vejamos, abaixo, a terminologia de parentesco em Mehináku. Esta terminologia está organizada em gerações e assinalada com as abreviações das nomenclaturas apresentadas anteriormente. No quadro, apresentamos o que significam os termos, a partir da visão de Ego Masculino ${ }^{3}$, bem como mostramos como os termos usados para nomear entes parentais podem mudar a depender da relação de parentesco que esse ente desempenhe dentro da sociedade Mehináku.

\section{Terminologia para Parentesco Consanguíneo}

$\mathrm{G}^{+4}$ Não há denominação terminológica acima de $\mathrm{G}^{+3}$, ou seja, tataravós são também referidos por Ego como atuku'mã ( $\left.{ }^{\prime}\right)$ e atsitfu'malu (ㅇ).

\begin{tabular}{|c|c|c|c|}
\hline \multirow[t]{2}{*}{$\mathrm{G}^{+3}$} & atuku'mã & FFF & Pai do pai do pai (bisavô) \\
\hline & atsitfu'malu & MMM & Mãe da mãe da mãe (bisavó) \\
\hline $\mathrm{G}^{+2}$ & a'tu & FF & Pai do pai (avô) \\
\hline & a'tsi & MM & Mãe da mãe (avó) \\
\hline $\mathrm{G}^{+1}$ & pa'pa & $\begin{array}{l}F \\
F B\end{array}$ & $\begin{array}{l}\text { Pai } \\
\text { Irmão do pai }\end{array}$ \\
\hline & mã'ma & $\begin{array}{l}M \\
M Z\end{array}$ & $\begin{array}{l}\text { Mãe } \\
\text { Irmã da mãe }\end{array}$ \\
\hline & $\begin{array}{l}\text { u'a ô } \\
\text { ku'ku } \odot\end{array}$ & MB & Irmão da mãe (tio) \\
\hline & $a^{\prime} k i$ & FZ & Irmã do pai (tia) \\
\hline
\end{tabular}

3 Estamos usando a visão de um Ego Masculino, representado adiante no esquema de laços por um triângulo preenchido (nas Figuras 1 e 2), porque nossos colaboradores de pesquisa, os sujeitos que nos forneceram os dados sobre parentesco, são falantes do sexo masculino, com idade entre 20 e 30 anos. 


\begin{tabular}{|c|c|c|}
\hline $\begin{array}{l}\text { nuta'pisu ỗ } \\
\text { nutu'kaka } \text { ? }\end{array}$ & $\begin{array}{l}\text { eB } \\
\text { FBeS } \\
\text { MZeS }\end{array}$ & $\begin{array}{l}\text { Irmão mais velho }\left(\mathrm{PrBio}^{4}\right) \\
\text { Filho mais velho do irmão do pai (PrPar) } \\
\text { Filho mais velho da irmã da mãe (PrPar) }\end{array}$ \\
\hline nutuka'kalus & $\begin{array}{l}\text { eZ } \\
\text { FBeD } \\
\text { MZeD }\end{array}$ & $\begin{array}{l}\text { Irmã mais velha (PrBio) } \\
\text { Filha mais velha do irmão do pai (PrPar) } \\
\text { Filha mais velha da irmã da mãe (PrPar) }\end{array}$ \\
\hline nu's $\varepsilon$ & $\begin{array}{l}\text { yB } \\
\text { FByS } \\
\text { MZyS }\end{array}$ & $\begin{array}{l}\text { Irmão mais novo (IrBio) } \\
\text { Filho mais novo do irmão do meu pai (IrPar) } \\
\text { Filho mais novo da irmã da minha mãe (IrPar) }\end{array}$ \\
\hline nu'scsu & $\begin{array}{l}\text { yZ } \\
\text { FByD } \\
\text { MZyD }\end{array}$ & $\begin{array}{l}\text { Irmã mais nova (IrBio) } \\
\text { Filha mais nova do irmão do pai (IrPar) } \\
\text { Filha mais nova da irmã da mãe (IrPar) }\end{array}$ \\
\hline $\begin{array}{l}\text { nũtanu'le } \\
\text { (C) }\end{array}$ & $\begin{array}{l}\text { MBeS } \\
\text { FZeS } \\
\text { MByS } \\
\text { FZyS }\end{array}$ & $\begin{array}{l}\text { Filho mais velho do irmão da mãe (primo) } \\
\text { Filho mais velho da irmã do pai (primo) } \\
\text { Filho mais novo do irmão da mãe (primo) } \\
\text { Filho mais novo da irmã do pai (primo) }\end{array}$ \\
\hline nũtanu'lefu & $\begin{array}{l}\text { MBeD } \\
\text { FZeD } \\
\text { MByD } \\
\text { FZyD }\end{array}$ & $\begin{array}{l}\text { Filha mais velha do irmão da mãe (prima) } \\
\text { Filha mais velha da irmã do pai (prima) } \\
\text { Filha mais nova do irmão da mãe (prima) } \\
\text { Filha mais nova da irmã do pai (prima) }\end{array}$ \\
\hline
\end{tabular}

4 Adotamos a seguinte legenda para classificar os irmãos: PrBio: primogênito/a biológico/a; PrPar: primogênito/a paralelo/a; IrBio: Irmão/a biológico/a; IrPar: Irmão/a paralelo/a.

5 Gregor (1982 [1977]) apresenta dois termos para a nomeação da irmã primogênita de Ego (eZ), tal como ocorre na nomeação do irmão primogênito (eB), são eles (na ortografia do próprio autor): (i) nutuka'kalu (para a forma como os irmãos mais novos se referem à irmã) e nuta'puju (para a forma como as irmãs mais novas se referem à irmã). Em nossa coleta de dados, os falantes nos disseram não existir essa diferença. 


\begin{tabular}{|c|c|c|c|}
\hline $\mathrm{G}^{-1}$ & nũ'taĩ & $\begin{array}{l}\text { S } \\
\text { BS } \\
\text { FBSS } \\
\text { MZSS }\end{array}$ & $\begin{array}{l}\text { Filho } \\
\text { Filho do irmão (filho) } \\
\text { Filho do filho do irmão do pai (filho) } \\
\text { Filho do filho da irmã da mãe (filho) }\end{array}$ \\
\hline & nĩtsu'palu & $\begin{array}{l}\text { D } \\
\text { BD } \\
\text { FBSD } \\
\text { MZSD }\end{array}$ & $\begin{array}{l}\text { Filha } \\
\text { Filha do irmão (filha) } \\
\text { Filha do filho do irmão do pai (filha) } \\
\text { Filha do filho da irmã da mãe (filha) }\end{array}$ \\
\hline & ni'wã & $\begin{array}{l}\text { ZS } \\
\text { FBDS } \\
\text { MZDS }\end{array}$ & $\begin{array}{l}\text { Filho da irmã (sobrinho) } \\
\text { Filho da filha do irmão do pai (sobrinho) } \\
\text { Filho da filha da irmã da mãe (sobrinho) }\end{array}$ \\
\hline & nũtami'tsui & $\begin{array}{l}\text { ZD } \\
\text { PBDD } \\
\text { MZDD }\end{array}$ & $\begin{array}{l}\text { Filha da irmã (sobrinha) } \\
\text { Filha da filha do irmão do pai (sobrinha) } \\
\text { Filha da filha da irmã da mãe (sobrinha) }\end{array}$ \\
\hline $\mathrm{G}^{-2}$ & nũ'hì & $\begin{array}{l}\text { SS } \\
\text { DS } \\
\text { BSS } \\
\text { BDS }\end{array}$ & $\begin{array}{l}\text { Filho do filho (neto) } \\
\text { Filho da filha } \\
\text { Filho do filho do irmão } \\
\text { Filho da filha do irmão }\end{array}$ \\
\hline & nu'wïtu & $\begin{array}{l}\text { DD } \\
\text { SD } \\
\text { BSD } \\
\text { BDD }\end{array}$ & $\begin{array}{l}\text { Filha da filha (neta) } \\
\text { Filha do filho } \\
\text { Filha do filho do irmão } \\
\text { Filha da filha do irmão }\end{array}$ \\
\hline $\mathrm{G}^{-3}$ & nũhiku'mã & $\begin{array}{l}\text { SSS } \\
\text { SDS } \\
\text { BSSS } \\
\text { BSDS }\end{array}$ & $\begin{array}{l}\text { Filho do filho do filho (bisneto) } \\
\text { Filho da filha do filho } \\
\text { Filho do filho do filho do irmão } \\
\text { Filho da filha do filho do irmão }\end{array}$ \\
\hline & nu'wĩtuku'malu & $\begin{array}{l}\text { DDD } \\
\text { SDD } \\
\text { BSSD } \\
\text { BSDD }\end{array}$ & $\begin{array}{l}\text { Filha da filha da filha (bisneta) } \\
\text { Filha da filha do filho } \\
\text { Filha do filho do filho do irmão } \\
\text { Filha da filha do filho do irmão }\end{array}$ \\
\hline
\end{tabular}


Não há denominação terminológica após $\mathrm{G}^{+3}$, ou seja, tataranetos são também referidos por Ego com a mesma terminologia usada para bisnetos e bisnetas.

O que podemos observar, pelas informações apresentadas acima, é que a principal relação de parentesco, aquela que afeta a terminologia linguística, se estabelece entre os tios e primos cruzados. Como fica evidente, tios paralelos são considerados pelo Ego como pais, e, portanto, são nomeados como pa'pa. Somente os tios cruzados, ou seja, aqueles de sexo oposto ao sexo dos pais biológicos de Ego, irão ser considerados, de fato, como tios, e serão nomeados como u'a (ô) /ku'ku (ㅇ).

Esse tipo de regra de relacionamento, que considera tios paralelos como pais, interdita o casamento entre primos paralelos, uma vez que os filhos do irmão do pai de Ego são considerados por Ego como irmãos, o que, do ponto de vista dos Mehináku, seria incestuoso e, portanto, proibido. Um homem não poderia casar com sua prima paralela, portanto, por considerá-la como sua irmã direta, como são os seus irmãos biológicos, filhos de seus pais biológicos.

Essa regra tem impacto direto, também, na nomeação dos demais entes parentais. Se observarmos as informações expostas, veremos que, por considerar o tio paralelo como pai, e a tia paralela como mãe, Ego assume a função não só de irmão dos primos paralelos, como também a função de pai dos filhos dos filhos do irmão do pai, e como pai dos filhos dos filhos da irmã da mãe. Os filhos dos primos paralelos, por sua vez, também irão considerar Ego como pai, assim como os netos dos primos paralelos irão considerar Ego como avô, e vice e versa.

Como sobrinhos propriamente ditos, restarão os filhos e filhas das primas cruzadas de ego, tanto por parte de pai quanto por parte de mãe (tio e tia cruzados de Ego), e os filhos e filhas do irmão da mãe e da irmã do pai, que, como dissemos, são tios cruzados. Nesses casos, o casamento é permitido entre os Mehináku, de modo que é comum relacionamentos matrimoniais entre um jovem e uma jovem que sejam primos cruzados.

Existe vigilância sobre essas regras de casamento em Mehináku, que se inicia desde a infância. É comum, por exemplo, ver primos cruzados brincando juntos na aldeia, se relacionando na adolescência ou mesmo fazendo piadas sobre namorar uns com os outros já no início da vida adulta, mas esse tipo de comportamento não é visto com bons olhos quando se trata da relação entre primos paralelos (considerados irmãos). Embora seja possível ver primos paralelos brincando juntos, mesmo que com menos frequência que os primos cruzados, há uma certa interdição entre eles, sobretudo na adolescência.

Outra questão interessante a ser vista em relação ao parentesco consanguíneo em Mehináku, é o modo como são nomeados os irmãos de Ego. Percebe-se que há uma 
diferença na nomeação de primogênitos em relação à nomeação dos demais irmãos, e também uma diferença no modo como os irmãos mais velhos são referidos (evocados) pelos mais novos. Vimos, acima, que há duas palavras para irmão mais velho, são elas: nuta' pişu e nutu'kaka, sendo a primeira usada pelos irmãos mais novos para evocar o irmão mais velho, e a segunda usada pelas irmãs mais novas para evocar o irmão mais velho. Essa diferença, a que separa os irmãos mais novos de acordo com o sexo no momento da referenciação a seus irmãos mais velhos, se perde, por sua vez, quando trata-se da irmã mais velha, que é referida tanto por irmãos, quanto por irmãs mais novas como nutuka'kalu, diferentemente do que havia proposto Gregor (1982 [1977]).

Pela análise do sistema de parentesco feita acima, e das terminologias utilizadas pelos falantes para assinalar as posições parentais, é possível afirmar que os Mehináku apresentam um sistema de parentesco do tipo Iroquês para a geração de Ego e sua geração ascendente, conforme abaixo:

Figura 2. Exemplo de esquema Iroquês, com marcação de Ego masculino

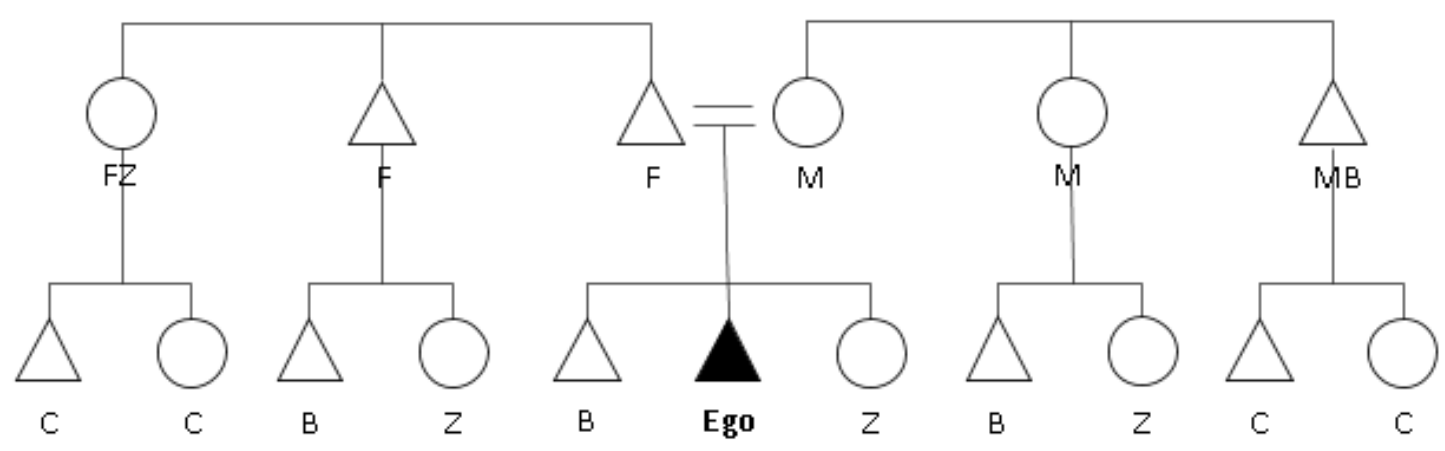

Fonte: Elaboração própria

Observando à direita: a irmã da mãe de Ego também é mãe de Ego e os filhos da irmã da mãe são irmãos e irmãs de Ego. O irmão da mãe é tio de Ego e os filhos e filhas do irmão da mãe são primos de Ego. Observando à esquerda: o irmão do pai de Ego também é pai de Ego e os filhos do irmão do pai são irmãos de Ego, ao passo que a irmã do pai de Ego é tia de Ego, sendo seus filhos primos de Ego. O esquema abaixo resume melhor essas informações, com relação à $\mathrm{G}^{0}$ e $\mathrm{G}^{+1}$ : 
Figura 3. Esquema de laço Iroquês dos Mehináku, com marcação de Ego masculino $\left(\mathrm{G}^{0}\right.$ e $\left.\mathrm{G}^{+1}\right)$

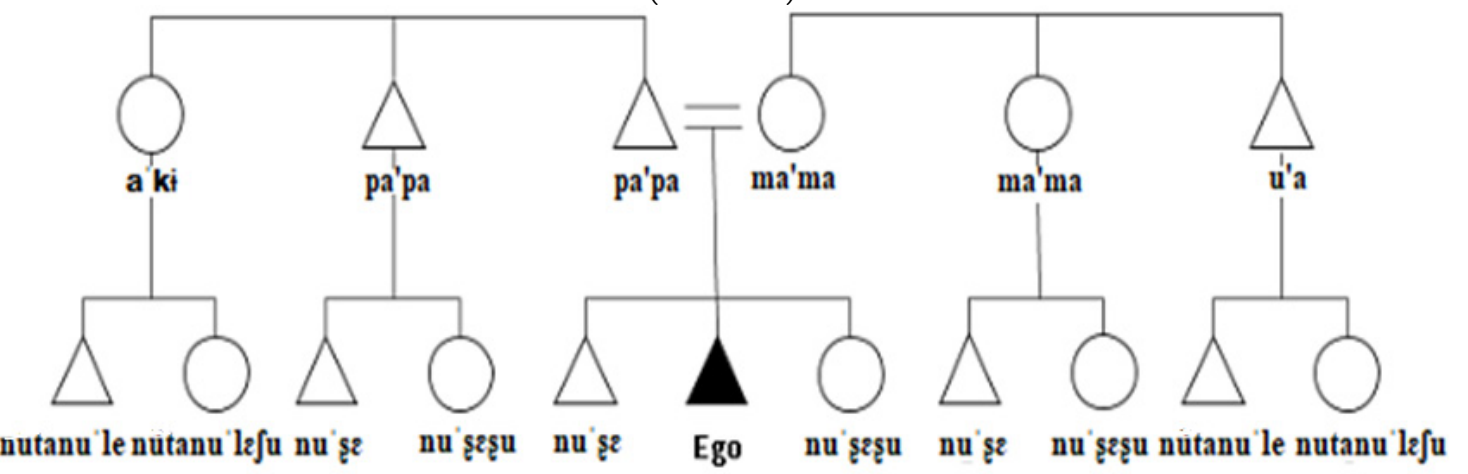

Fonte: Elaboração própria

É importante tratar, também, da relação que há entre a geração de Ego e a geração descendente, sobretudo porque, por conta da interdição do casamento entre primos paralelos, por serem considerados irmãos, a terminologia de parentesco sofre algumas alterações interessantes, sobre as quais trataremos logo abaixo. A figura a seguir resume as informações apresentadas na tabela anterior:

Figura 4. Esquema de laço Iroquês dos Mehináku, com marcação de Ego masculino $\left(G^{0}, G^{+1}\right.$ e $\left.G^{-1}\right)$

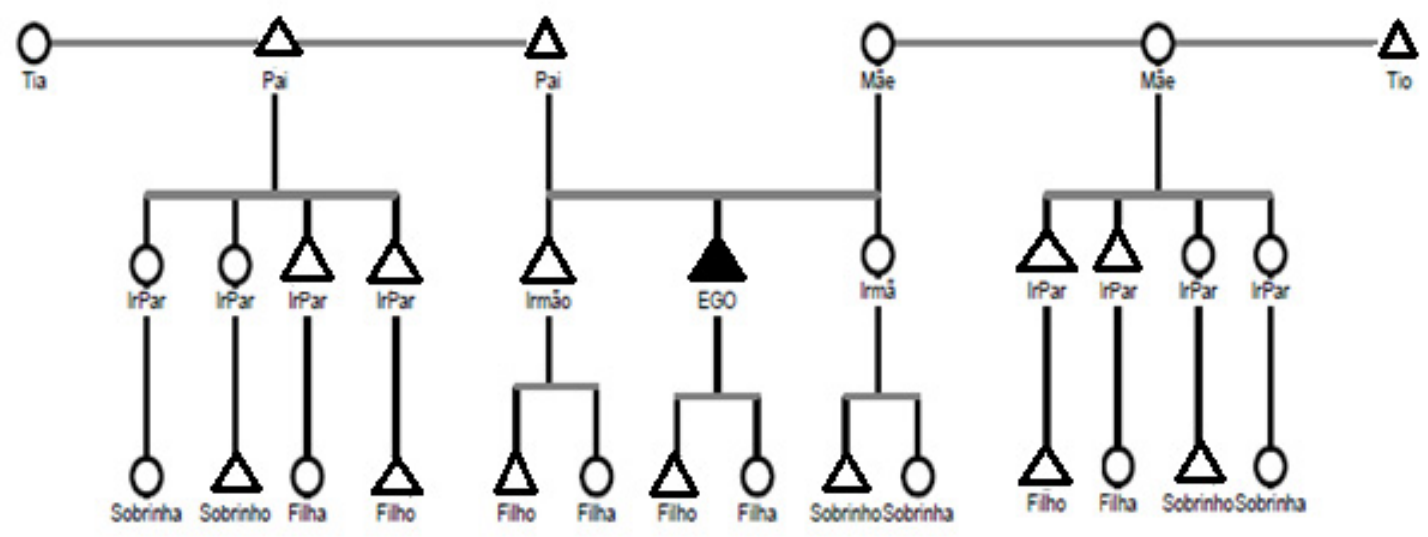

Fonte: Elaboração própria

É possível observar, pela figura acima, que ocorre uma mudança terminológica (que reflete o comportamento parental dos indígenas) no processo de referência/evocação em Mehináku na geração descendente de Ego. Para além das diferenças que vimos na geração ascendente, que enquadra o sistema terminológico da língua no modelo Iroquês, é possível ver também os desdobramentos desse sistema a partir da geração descendente de Ego. 
Dentre as observações que podemos fazer, estão: (i) os filhos de Ego serão sempre os filhos dos seus irmãos, sejam eles biológicos ou paralelos; (ii) os sobrinhos de Ego serão sempre os filhos de suas irmãs, sejam elas biológicas ou paralelas; (iii) os filhos de Ego e os filhos dos irmãos paralelos de Ego (filhos do irmão do pai de Ego e da irmã da mãe de Ego) chamarão Ego de pai (pa'pa); (iv) os filhos das irmãs biológicas de Ego e das irmãs paralelas de Ego (filhas do irmão do pai de Ego e da irmã da mãe de Ego) chamarão Ego de tio ( $\left.u^{\prime} a\right)$; ( v) os filhos das irmãs do pai e dos irmãos da mãe serão considerados como primos por Ego, podendo assim haver casamento entre eles (obedecendo a regra matrimonial que licencia o casamento entre primos cruzados e interdita entre primos paralelos, considerados irmãos) e (vi) os filhos das irmãs do pai e dos irmãos da mãe chamarão Ego de primo, estando as primas liberadas para casamento com ele.

\section{Considerações finais}

Nosso objetivo, neste trabalho, foi apresentar o sistema terminológico de parentesco consanguíneo em Mehináku, a fim de que o leitor pudesse compreender a complexidade que se experimenta na análise do sistema de atribuições e nomeações parentais desse povo. Esperamos que este trabalho possa contribuir para o entendimento da relação entre a terminologia de parentesco e as práticas parentais, que é tão caro para a linguística e para a antropologia, e para o conhecimento linguístico dos termos usados na nomeação dos entes familiares, que é fundamental para possíveis reconstruções históricas, comparações entre línguas da mesma família, dentre outros aspectos.

\section{Agradecimentos}

Este trabalho teve apoio da Fundação de Amparo à Pesquisa do Estado de São Paulo (FAPESP), processo n. 2016/18391-4.

\section{REFERÊNCIAS}

ALMEIDA, M. W. B. Lewis Morgan: 140 anos dos Sistemas de Consanguinidade e Afınidade da família humana (1871-2011). Cadernos de Campo, São Paulo, n. 19, p. 1-384, 2010.

COELHO DE SOUZA, M. S. Da complexidade do elementar: para uma reconsideração do parentesco xinguano. In: VIVEIROS DE CASTRO, E. (org.). Antropologia do Parentesco. Rio de Janeiro: Editora UFRJ, 1995. p. 121-206.

COELHO DE SOUZA, M. S. Faces da afinidade: um estudo bibliográfico do parentesco xinguano. 1992. Dissertação (Mestrado) - Faculdade de Letras, Universidade Federal do Rio de Janeiro, Rio de Janeiro, 1992. 
DUMONT, L. Introducción a dos teorias de la antropología social. Barcelona: Editorial Anagrama, 1975.

FLORIDO, M. P. As parentológicas Arawá e Arawak: um estudo sobre parentesco e aliança. 2008. Dissertação (Mestrado em Antropologia) - Faculdade de Filosofia, Letras e Ciências Humanas, Universidade de São Paulo, São Paulo, 2008.

FRANCHETTO, B.; HECKENBERGER, M. Os povos do Alto Xingu: história e cultura. Rio de Janeiro: Editora da UFRJ, 2001.

GREGOR, T. Mehináku: o drama da vida diária numa aldeia do Alto Xingu. São Paulo: Cia Nacional, 1982.

GREGOR, T. Social relationships in a small society: a study of the mehinacu Indians of Central Brazil. 1963. Dissertation (Ph.D) - Columbia University, Columbia, 1963.

GALVÃO, E. Cultura e sistema de parentesco das tribos do alto rio Xingu. Boletim do Museu Nacional, Nova série, Antropologia, n. 14, p. 1-56, 1953.

ISA. Enciclopédia dos povos indígenas no Brasil. Versão eletrônica, 2008.

LÉVI-STRAUSS, C. As estruturas elementares do Parentesco. Petrópolis: Vozes, 1982.

LÉVI-STRAUSS, C. O futuro dos estudos de parentesco. In: LARAIA, R. B. (org.). Organização Social. Rio de Janeiro: Zahar, 1969 [1965]. p. 22-55.

LOPES, T. T. C.; FERREIRA, M. N. Terminologia de parentesco em Parkatejê. Espaço Ameríndio, Porto Alegre, v. 9, n. 1, p. 10-34, 2015.

LOWIE, R. A note on relationships terminologies. American Anthropologist, v. 30, n. 2 , p. 263-267, 1928.

McLENNAN, J. Primitive Marriage. London: Routledge Press, 1998 [1865].

MORGAN, L. Ancient Society: researches in the lines of human progress from savagery through barbarism to civilization. London: Routledge Press, 1998 [1878]. 
MORGAN, L. Systems of Consanguinity and Affinity of the Human Family. Lincoln: University of Nebraska Press, 1997 [1871].

MURDOCK, G. P. Social Structure. New York: The MacMillan Company, 1949.

RADCLIFFE-BROWN, A. Preface. In: FORTES, M.; EVANS-PRITCHARD, E. E. (org.). African Political Systems. London: Oxford University Press, 1966. p. vi-xiii.

RADCLIFFE-BROWN, A. O método comparativo em antropologia estrutural. Coleção grandes cientistas sociais. São Paulo: Ática, 1978.

RADCLIFFE-BROWN, A. Estrutura e função na sociedade primitiva. Petrópolis: Vozes, 1973.

RADCLIFFE-BROWN, A. The study of kinships systems. The Journal of the Royal Anthropological Institute of Great Britain and Ireland, v. 71, n. 1/2, p. 1-18, 1941.

RODRIGUES, A. D. Notas sobre o sistema de parentesco dos índios Karirí. Revista Brasileira de Linguística Antropológica, v. 4, n. 2, p. 237-250, 2012.

RIVERS, W. R. Terminologia classificatória e matrimônio com primo cruzado. In: CARDOSO DE OLIVEIRA, R. A antropologia de Rivers. Campinas: Editora da Unicamp, 1991a [1913]. p. 71-94.

SILVA, M. Parentesco e Organização social na Amazônia: um rápido esboço. Anuário de Estudios Amerindios, Sevilla, v. 61, n. 2, p. 649-679, 2004.

SILVA, M. Tempo e espaço entre os Enawene-nawe. Revista de Antropologia, São Paulo, v. 41, n. 2, 1998 [não paginado].

VIVEIROS DE CASTRO, E. Antropologia do Parentesco. Rio de Janeiro: Editora da UFRJ, 1995 